\title{
A FUNÇÃO SOCIAL DA EDUCAÇÃO AMBIENTAL NAS PRÁTICAS COLABORATIVAS: PARTICIPAÇÃO E ENGAJAMENTO
}

\author{
Pedro Roberto Jacobi \\ Martha Tristāo* \\ Maria Isabel Gonçalves Correa Franco ${ }^{* * *}$
}

\begin{abstract}
RESUMO: A participação como eixo norteador das práticas sociais de educação ambiental coloca como necessidade a articulação de saberes e fazeres para responder às complexas questôes socioambientais. Este artigo desenvolve uma reflexão crítica sobre as práticas socioambientais educativas de caráter coletivo e colaborativo, com dinâmicas abertas e vivenciais, que têm se revelado como processos importantes na produção de uma cultura de diálogo, de participação, de mobilização e de potência de ação. Enfatizam-se as abordagens integradoras das relações entre as dimensões subjetivas e intersubjetivas e a possibilidade de estimularem a constituição de identidades coletivas e de comunidades em espaços de convivência. Isso abre caminhos para incrementar o potencial educativo de espaços dentro e fora da escola que podem se tornar contextos possíveis de diálogos democráticos, mediando experiências de diferentes sujeitos, protagonistas locais na construção de projetos de intervenção coletivos.
\end{abstract}

Palavras-chave: Educação ambiental. Participação social. Mobilização.

Doutor em Sociologia e professor da Universidade de São Paulo (USP).

E-mail: pedro.jacobi@pq.cnpq.br

** Doutora em Educação e professora da Universidade Federal do Espírito Santo (UFES).

E-mail:martha@npd.ufes.br

*** Doutoranda em Educação e professora do Instituto Nacional de Pós-Graduação de São Paulo (INPG).E-mail: isabel.gfranco@uol.com.br 
A função social da educação ambiental nas práticas colaborativas...

THE SOCIAL FUNCTION OF ENVIRONMENTAL EDUCATION IN COLLABORATIVE PRACTICES: PARTICIPATION AND ENGAGEMENT

ABSTRACT: Participation as a guiding reference of social practices of environmental education creates the need to articulate knowledge and actions to respond to socioenvironmental issues that have become more complex and environmental risks that intensify. The article develops a critical approach around socio-environmental educative practices within a collective and collaborative approach, emphasizing a culture of dialog, participation, mobilization and potence of action. The emphasis is on the relations between subjective and intersubjective dimensions, and its potential to stimulate the creation of collective identities and communities. This increments the educational potential of spaces within and outside schools, as contexts of horizontal dialogues, mediating experiences of different social local leading persons in the construction of projects of collective intervention.

Key words: Environmental education. Social participation. Mobilization.

\section{Introdução}

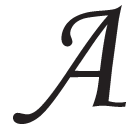

multiplicação dos riscos, em especial os ambientais e tecnológicos de graves consequências, é o elemento-chave para entender as características, os limites e as transformações da nossa modernidade. A sociedade, produtora de riscos, torna-se cada vez mais reflexiva, mais autocrítica, e o conceito de risco passa a ocupar um papel estratégico para entender as características, os limites e as transformaçōes do projeto histórico da modernidade (Beck, 1997). A nova realidade globalizada da modernidade gera crescente incerteza, mutabilidade e reflexividade.

A reflexão sobre "sociedade de risco" permite abordar a complexa temática das relações entre sociedade, meio ambiente e educação. Esta envolve um conjunto de atores do universo educativo em todos os níveis, promovendo a articulação dos diversos sistemas de conhecimento, a formação de professores e sua profissionalização e a crescente presença de uma perspectiva interdisciplinar na reflexão e ação.

Vive-se, sobretudo a partir da Primeira Conferência das Nações Unidas sobre Meio Ambiente e Desenvolvimento, em Estocolmo 
(1972), uma emergência socioambiental, que aponta para a necessidade de compatibilizar as atividades humanas e o crescimento econômico com a manutenção ecossistêmica (Veiga, 2007). A visibilidade da problemática ambiental tem contribuído para fazer emergir, no cenário mundial, inúmeras reflexões que colocam em tela as formas de relações sociais, meio ambiente e produção.

A sociedade pós-industrial, então, confronta-se com uma crise que, mais do que ecológica ou material, é uma crise de valores, do estilo de pensamento, dos imaginários sociais, dos pressupostos epistemológicos e do conhecimento que sustentaram a modernidade. A simplificação das análises concentradas na racionalidade ocidental não consegue dar conta da complexidade do mundo. Beck (1997) designa esta, além de pós-tradicional ou pós-industrial, como sociedade pósracional, no sentido de que perdemos a certeza na razão instrumental, embora os riscos tenham sua origem na ordem instrumental da razão (Tristão, 2005).

Uma emergência que se reflete em crise do ser no mundo, que se manifesta em toda sua plenitude: nos espaços internos do sujeito, nas condutas sociais autodestrutivas e no incessante processo de degradação da natureza e da qualidade de vida das pessoas. A sua essência é a incerteza, e isso terá maior ou menor impacto de acordo com a forma como a sociedade define o seu padrão de desenvolvimento e os padrōes de responsabilidade, segurança, controle, limitação do dano e distribuição das consequências do dano, levando em conta as ameaças potenciais.

Num contexto marcado pela degradação permanente do meio ambiente e dos seus ecossistemas, chama a atenção a prevalência da racionalidade cognitivo-instrumental que agravou a situação ambiental do planeta. Disseminou a idéia de dominação da natureza e do seu uso, ignorando a função do contexto num processo linear compartimentado e compartimentalizador do conhecimento e das práticas sociais. Essa problemática envolve um conjunto de atores do universo educativo em todos os níveis. Abre a possibilidade de potencializar outras racionalidades para o engajamento dos diversos sistemas de conhecimento, da formação e profissionalização docente, de profissionais em geral e da comunidade universitária. Isso se concretiza pela adoção de uma abordagem metodológica interdisciplinar, da complexidade do conhecimento baseado em 
A função social da educação ambiental nas práticas colaborativas...

valores e práticas sustentáveis, indispensáveis para estimular o interesse e o engajamento de cidadãos e cidadãs na ação e na responsabilização.

É cada vez mais notória a complexidade do processo de transformação de uma sociedade crescentemente não só ameaçada, mas diretamente afetada por riscos e agravos socioambientais, onde a dimensão da sustentabilidade se apresenta como alternativa. Assim, a idéia de sustentabilidade implica a necessidade de definir uma limitação, quanto às possibilidades de um crescimento desordenado, e implementar um conjunto de iniciativas que levem em conta a existência de interlocutores e participantes sociais relevantes e ativos, por meio de práticas educativas e de um processo de diálogo informado mútuo, o que reforça um sentimento de co-responsabilização e de constituição de valores éticos.

A sustentabilidade socioambiental ultrapassa o enfoque economicista do desenvolvimento, ressignifica as práticas sociais e econômicas (Caride \& Meira, 2001). Nesse sentido, o conceito de desenvolvimento sustentável ${ }^{1}$ somente pode ser entendido como um processo onde, de um lado, as restriçõos mais relevantes estão relacionadas com a exploração dos recursos, a orientação do desenvolvimento tecnológico e o marco institucional (Jacobi, 1997). De outro, entram em pauta as consideraçôes imprescindíveis às diferentes culturas, relações sociais, as múltiplas referências e experiências tradicionais e vocações locais, em contraposição ao modelo de desenvolvimento econômico e tecnológico como controle, resposta e saída aos impasses ambientais.

Atualmente, o avanço rumo a uma sociedade assentada em valores de sustentabilidade é permeado de conflitos e as causas básicas que provocam atividades ecologicamente predatórias podem ser atribuídas às instituições sociais, aos sistemas de informação e de comunicação e aos valores individualistas, competitivos e consumistas adotados pela sociedade contemporânea. Consequentemente, isto implica a necessidade de estimular uma participação mais ativa da sociedade como uma forma de estabelecer um conjunto socialmente identificado de problemas, objetivos e soluções (Jacobi, 1997; Guimarães, 2001).

A sustentabilidade como novo critério básico e integrador pode fortalecer valores coletivos e solidários, a partir de práticas educativas contextualizadoras e problematizadoras que, pautadas pelo paradigma da complexidade, aportem para a escola e para outros ambientes pedagógicos uma atitude de ação-reflexão-ação em torno da problemática ambiental. 
As práticas educativas ambientalmente sustentáveis nos apontam para propostas pedagógicas centradas na criticidade e na emancipação dos sujeitos, com vistas à mudança de comportamento e atitudes, ao desenvolvimento da organização social e da participação coletiva. Nessa proposta de educação reflexiva e engajada, centrada nos saberes e fazeres construídos com e não para os sujeitos aprendentes e ensinantes, a educação ambiental difere substancialmente da informação ambiental. Esta ainda é focada na elaboração e transmissão de conteúdos descontextualizados e "despolitizados", no sentido de instaurar mudanças efetivas na realidade através da tessitura de um conhecimento crítico, intencionalmente engajado.

O desafio que se apresenta é o de elaborar, nos espaços institucionais da educação, novas epistemologias que possibilitem "uma reforma do pensamento" (Morin, 2000) para um conhecimento-emancipação (Santos, 2000), e a educação a criar espaços de convivência que, como diz Maturana (1998), em outras palavras, organismo e meio desencadeiam mudanças estruturais sob as quais são reciprocamente congruentes, numa relação de interdependência mútua, de adaptação e de organização ecossistêmica.

Essa mudança paradigmática implica uma mudança de percepção e de valores, gerando um saber solidário e um pensamento complexo, aberto às indeterminações, às mudanças, à diversidade, à possibilidade de construir e reconstruir num processo contínuo de novas leituras e interpretações, configurando novas possibilidades de ação.

A premissa que norteia o paradigma proposto é o diálogo de saberes que permita construir espaços de fronteiras; formar um pensamento crítico, criativo e sintonizado com a necessidade de propor respostas para o futuro, capaz de analisar as complexas relaçôes entre os processos naturais e sociais e de atuar no ambiente em uma perspectiva global, respeitando as diversidades socioculturais. O objetivo é o de propiciar novas atitudes e comportamentos face ao consumo na nossa sociedade e de estimular a mudança de valores individuais e coletivos (Jacobi, 1997; 2005).

As experiências e práticas educativas e de pesquisa interdisciplinares ainda são recentes e incipientes. Os processos de conhecimento buscam estabelecer cortes transversais na compreensão e explicação dos contextos de aprendizagem e de formação. O estímulo é para a 
A função social da educação ambiental nas práticas colaborativas...

interação e interdependência entre as disciplinas e, consequentemente, entre as pessoas para o desenvolvimento de metodologias interativas.

\section{Práticas educativas inovadoras e colaborativas}

O conceito de Aprendizagem Social (Social Learning) é parte componente deste artigo como um processo que tenta responder aos desafios da sustentabilidade e integração das interfaces da gestão ambiental participativa. Isso pressupõe a contribuição das diversas áreas de conhecimentos, numa abordagem metodológica multirreferencial e interdisciplinar para a compreensão das interfaces e abrangência do campo educativo-ambiental. A noção básica é definida como "aprender junto para compartilhar” (HarmoniCop Project, 2003). Este trabalho colaborativo promove a reflexão crítica, a participação coletiva e o diálogo entre os atores envolvidos na gestão participativa.

Nos processos educativos dentro da escola, os referenciais da Aprendizagem Social se inserem nas práticas socioambientais educativas de caráter colaborativo, que têm se revelado como veículo importante na construção de uma nova cultura de diálogo e participação (Arnstein, 2002). Como práxis educativa engajada e política, abre um estimulante espaço para a construção e criação de eixos interdisciplinares, em torno dos quais se tece uma nova cultura para a formação abrangente, a partir de uma abordagem sistêmica e complexa.

Essa abordagem, integradora das relações entre as esferas subjetivas e intersubjetivas, amplia a possibilidade de constituição de identidades coletivas em espaços de convivência e debates, criando situações de confrontação entre a autonomia individualista. Como sugere Dallari (2003), quando discorre sobre o homem em sua reflexão sobre participação, o ser humano é associativo. Quando faz referência a Aristóteles, argumenta que é um animal social, um animal político, ou seja, a espécie humana existe na convivência, pois não só vivemos como necessariamente precisamos conviver e este é um detalhe que foi esquecido.

Isso abre caminhos para incrementar o potencial da escola que, embora atrelada ao institucional, pode se tornar um espaço possível de convivência de uma cultura política em seu sentido amplo. Através da ampliação das áreas de intervenção de cidadãos e cidadãs nas práticas 
sociais, de diálogos horizontalizados, de aprendizagem do exercício da democracia participativa, a escola pode mediar experiências de diferentes sujeitos protagonistas de saberes e fazeres locais na construção de projetos de intervenção coletivos.

Nesse sentido, como sugere Giroux (2003), a cultura política está inextricavelmente ligada a questões de poder e de protagonismo. Citando Grossberg, aponta que o protagonismo envolve relações de participação e de acesso, envolve também as possibilidades de moverse em locais específicos de atividade e de poder, e de pertencer a eles, de modo a ser capaz de exercer seus poderes. Assim, Giroux abre caminho para outra perspectiva crítica da educação ambiental, a possibilidade de elaborar um projeto pedagógico que seja capaz de aprofundar os valores necessários à vivência de espaços de diálogos e aprendizagens de processos de democracia participativa na escola, em estreita vinculação com os movimentos sociais, por meio de estratégias metodológicas colaborativas e participativas, de vivência e experimentação real do espaço territorial/ambiental, social, político e cultural. Essa é uma perspectiva que possibilita também aos professores e professoras se envolverem em projetos onde seu trabalho se torne potencialmente transformador, ressignificando conhecimento e vida, ação mobilizadora e co-responsabilidades.

Esse "saber fazer coletivo" configura-se em importantes estratégias que englobam um conjunto de sujeitos e práticas, e pode ser um elemento na construção e criação de pactos de governança, fomentando a compreensão e o acolhimento de outros valores na superação das ações de regulação e de controle. Podem, assim, informar e intervir em novas escolhas do poder público e da sociedade rumo à sustentabilidade socioambiental.

O processo de aprendizagem social ambientalmente orientada implica em reconhecer e explicitar os conflitos originários das questôes ambientais; entender o meio ambiente como bem público e o acesso a um ambiente saudável como um direito de cidadania. Neste caso, seria, como propõe Bauman (2001), redesenhar e repovoar a quase vazia ágora - o lugar de encontro, debate e negociação entre o individuo e o bem comum, o público e o privado. Nesse sentido, quanto mais amplo for o domínio da política, mais amplo será o espraiamento do poder e, consequentemente, a participação (Tristão, 2005). 
Dessa forma, o pensamento, a capacidade de reflexividade, de conhecer o mundo, de tomar decisões, fazer escolhas e transformar veemse ampliados pela intencionalidade dos processos educativos. Estes colocam em pauta práticas educativas capazes de integrar relações e ações sociais de caráter colaborativo em contextos significativos, que aliam saberes e práticas sociais cotidianas de intervenção na realidade local. Integram, assim, as noções de comunidade, de espaço público, sujeito e aprendizagem social, potencializam ações coletivas na constituição de protagonistas e na sua capacidade de diálogo, reflexão e ação. Trata-se de admitir que o aprendizado é, por essência, uma relação sociocultural e histórica; sendo assim, é necessário que se leve em conta todos os contextos em que se apresentam esses fenômenos.

Partindo dessa concepção, a educação ambiental elimina fronteiras entre escola e comunidade, ao tomar como eixo do trabalho pedagógico a problemática socioambiental. Considera como espaços/tempos educativos o que acontece dentro e fora da escola, como lócus privilegiado, integrado e essencial para a criação de processos colaborativos de resolução de problemas locais, num movimento essencial em sintonia com temas da contemporaneidade, associados com a crise ambiental em escala planetária. A escolha e seleção de temáticas ambientais e as identidades dos sujeitos locais envolvidos são componentes pedagógicos fundamentais e fatores relevantes na construção de práticas educativas e criação de situações de aprendizagens calcadas na experiência e na vivência.

Nossa argumentação visa reforçar que as práticas educativas, articuladas com a problemática ambiental, não devem ser vistas como um adjetivo, mas como parte componente de um processo educativo que reforce um pensar da educação e dos educadores e educadoras orientados para a sustentabilidade (Jacobi, 2005).

Estas práticas, em última análise, se baseiam em: promoção de uma atitude contextualizadora e problematizadora da realidade, uma compreensão complexa e politizada da dimensão ambiental, a participação coletiva e o engajamento dos sujeitos. Isso explicita uma ênfase em práticas sociais menos rígidas, mais abertas às incertezas e mais vivenciais, centradas na cooperação entre os protagonistas. Portanto, a dimensão ambiental representa a possibilidade de lidar com conexôes entre diferentes dimensões humanas, entrelaçamentos e trânsitos entre múltiplos saberes e fazeres. Trata-se de um processo intelectual, 
enquanto aprendizado social, baseado no diálogo e interação em constante movimento de recriação e re-interpretação de saberes, informaçôes, conceitos e significados. A abordagem do meio ambiente passa a ter um papel articulador de religação dos conhecimentos, no contexto onde os conteúdos são também ressignificados. Ao interferir no processo de aprendizagem sobre as condutas cotidianas que afetam a qualidade de vida, em todas as formas e dimensões, a educação ambiental promove saberes e fazeres para novas leituras da realidade.

Educação ambiental, metodologias participativas e os espaços de convivência, finalidades e estratégias de cooperação

A educação ambiental transformadora, articulada com a mudança social, transforma a pedagogia em uma prática política, como sugere Giroux (2003), com uma cooperação entre educadores/as e outros sujeitos culturais engajados na lutas sociais e ambientais, criando espaços críticos de aprendizagem dentro e fora da escola, buscando a união com movimentos sociais organizados. Assim, as mudanças não ocorrerão de cima para baixo, mas com a participação direta de alunos/as, professores/as, comunidade, meio ambiente, numa dinâmica complexa (Tristão, 2007).

A formação em educação ambiental, então, passa a ser compreendida como uma rede de contextos que, desde a formação inicial ou escolar, estende-se à vivência, à atuação profissional, à participação em fóruns, cursos, grupos e eventos, estes compreendidos como espaços de convivência constituintes de processos formativos.

Esses movimentos marcantes de convergência dos encontros e eventos de educação ambiental são espaços/tempos de aprendizagens, de formação crítica e de criação. Aqui fazemos uma associação com as comunidades interpretativas de Santos (2000), que ocorrem quando há uma ampliação do discurso argumentativo nos auditórios relevantes da retórica, ou seja, abrem-se possibilidades de superação do monopólio interpretativo e do conhecimento de uma só via.

Tratamos os encontros e eventos de educação ambiental dentro de um sentido educacional e ambiental que eles podem ter, entrecruzando-se com situações e acontecimentos fazedores de história, como contextos educacionais de comunidades interpretativas e de 
A função social da educação ambiental nas práticas colaborativas...

solidariedade ao movimento ambientalista, e destes à sociedade. São também iniciadores de formação em educação ambiental para pessoas que se sensibilizam, se mobilizam e participam desse debate. Esses espaços de convivência, como recursos teóricos e metodológicos para a educação ambiental, validam as manifestações dos sujeitos, as imagens a partir dos encontros, das experiências, das trocas, das vivências e dos seus desdobramentos como contextos de aprendizagem, para além do que se poderia defini-los por sua possibilidade instrumental ou pragmática (Tristão \& Fassarela, 2006).

As instâncias participativas consultivas e/ou deliberativas das políticas ambientais podem ser consideradas instâncias abertas a essas conexôes educativas, a exemplo dos conselhos de meio ambiente, dos comitês de gestão de bacias hidrográficas e das audiências públicas, que podem cumprir o papel de serviço à democracia e à proteção ambiental (Jacobi, 2004). Mas também os encontros e eventos de articulação intelectual e política em que se dê visibilidade e continuidade às discussões sobre a gestão ambiental participativa. Essas formas educativas de engajamento na transversalidade dos grupos, dos interesses, dos movimentos sociais, culturais, na vida, são tessituras que flexibilizam e potencializam politicamente as estruturas rígidas de formação do sujeito e de seus grupos de pertencimento.

A articulação dos processos de elaboração da Agenda 21 escolar pode ser inserida dentro das premissas que norteiam o desenvolvimento, o envolvimento e o engajamento coletivo de toda comunidade escolar. No âmbito da escola, o que está em jogo é a construção de propostas e açôes socioeducativas que incentivem o exercício de uma educação problematizadora, contextualizada e interdisciplinar, que $e d u$ que o conhecimento, para que o sujeito da ação pedagógica possa inserir-se politicamente no mundo, de forma consciente, responsável e solidária.

Dessa maneira, a elaboração da Agenda 21 na escola pode ser uma estratégia interessante, que se insere no quadro das práticas educativas que ampliam a compreensão de contextos de aprendizagem e a relevância de processos e metodologias realmente dialógicos e participativos. As práticas educativas assim orientadas nascem de um movimento pedagógico que parte dos espaços cotidianos e de suas demandas, dinâmica que facilita aos educadores e educadoras enxergarem 
diferentes contextos de aprendizagem, além dos livros didáticos e quadros de giz (Franco, 2006).

As práticas reflexivas de educação ambiental buscam uma educação que assuma a complexidade, a globalidade, a criticidade e a responsabilidade pelo destino comum da humanidade, sem desrespeitar as identidades culturais e a diversidade das múltiplas sociedades que fazem parte do planeta. Nesse sentido, Paulo Freire valoriza a ética universal do ser humano; não a ética do mercado, que estimula o consumismo, o individualismo e a competitividade, mas a ética da solidariedade entre os seres humanos e com a vida.

A partir desses pressupostos críticos, a educação ambiental centra-se em objetivos e ações para a criação de espaços de convivência, onde se destaca a importância de contextos reais de vida e de práticas cotidianas na tessitura de conhecimentos capazes de mudar a realidade social. Os projetos podem criar esses espaços grupais e priorizar temas que surjam das demandas da comunidade educativa, ${ }^{2}$ como o grave problema do saneamento básico, por exemplo, e a ênfase na água como tema de relevância social. Isso transcende o conteúdo descontextualizado e fragmentado, geralmente abordado nos livros didáticos, dos ciclos hidrológicos, de sua composição química. Nesse caso, a educação ambiental abrange os problemas ligados a sua complexidade, à escassez, contaminação, distribuição, legislação etc., num processo educativo dinâmico que extrapola o controle das ideias.

A metodologia participava e dialógica proposta na educação ambiental pode desencadear um movimento inovador, fortalecendo o papel político da escola, ao envolver as bases da comunidade. Nesse movimento, os temas gestão ambiental participativa, distribuição de água, contaminação e escassez, por exemplo, são focados primeiramente no diagnóstico da situação no bairro, cuja abordagem se pauta nos princípios de uma pesquisa participante. Assim, configuram-se em laboratórios vivos para processos de ensino e aprendizagem, tecendo outras possibilidades temáticas a partir das vivências cotidianas dos protagonistas.

Alguns conteúdos ou eixos temáticos que considerem os saberes locais podem ser significativos para unir a coletividade e ampliar, por meio das ações existentes ou criadas, a mobilização e a participação, sendo a escola a mediadora e catalisadora no processo. 
A função social da educação ambiental nas práticas colaborativas...

Nessa proposta de práxis educativa tecida a muitas mãos e ideias, a incorporação da noção de currículo vivido no cotidiano, tão pertinente à educação ambiental engajada, facilita a necessária recontextualização de saberes locais cotidianos ao passar para o campo da educação, mediada pela percepção de conteúdo e currículos como leitura $d a$ e $n a$ ação da realidade.

Para fazer face aos desafios que se apresentam, como é o caso da problemática dos recursos hídricos, coloca-se a necessidade de ressignificar teoria e prática pedagógica, num projeto de abertura ao mundo da vida, para ser conhecido, interpretado e reapropriado nas escolas e nas comunidades, pelo conjunto de sujeitos aprendentes - professores, funcionários e alunos, e as comunidades através da mediação da escola na criação de fóruns de debates e produção de propostas e projetos que envolvam os espaços onde a escola está inserida e "pertence".

Isso cria a possibilidade de desenvolver uma práxis pedagógica que potencializa pensamento e ação reflexiva desses sujeitos-agentes do ensino e aprendizagem. Também os prepara para transformar a realidade a partir do conhecimento escolar, entendido nesse amplo processo de conhecimento como tessituras das dimensões histórica, política e cultural, desenvolvido em diferentes contextos sociais e materiais.

Esse "fazer educacional" contextualizado torna imprescindível tratar os cotidianos escolares a partir de necessidades coletivas, sociais, ampliando o desenvolvimento cognitivo dos alunos, sua autoestima e capacidade de relacionamentos, interações e afetividade, por meio de atividades de aprendizagens propostas através de múltiplas problematizações, em diferentes contextos (Franco, 2006).

Os encontros, eventos e fóruns constituem-se assim num conjunto de estratégias metodológicas de caráter participativo em escala microrregional, regional, nacional, quiçá internacional. Como exemplo desses fóruns, pode-se organizar a Agenda 21 como uma agenda socioambiental construída como um pacto entre escola e comunidade. Isso requer, para a sua efetiva concreção, o envolvimento e o comprometimento dos participantes do projeto, com ações de melhoria das condições de vida da comunidade educativa, isto é, do conjunto educativo formado nas relações sociedade-escola. ${ }^{3}$

Em processos de construção prática, esse conjunto de sujeitos protagonistas locais, escola e bairro, se reúnem para a identificação de 
problemas e propostas de soluções, geradas em contextos de diálogo e participação, onde todas as experiências e conhecimentos são considerados. Escolhe, através da negociação, que processos, estratégias e planos de ação produzem benefícios à comunidade onde vivem, atuam e/ou trabalham, quais os processos de colaboração e que espaços serão envolvidos. Todos têm a oportunidade de aprender e ensinar, tornando-se fazedores de histórias, multiplicadores de conhecimentos, experiências e iniciativas no seu bairro: uma comunidade que se educa, educando, ao elaborar os diagnósticos e açóes a partir de suas próprias demandas.

\section{Considerações finais}

A criação de espaços de convivência nas escolas pode representar uma proposta pedagógico-metodológica que considera como contextos de vivência e convivência de aprendizagens não só o "ambiente escolar", mas o cotidiano de uma realidade que se abre ao local e ao planetário. Para tanto, se propõe a elaboração de fóruns permanentes como práticas educativas e democráticas, através da ecologia de saberes numa extensão ao contrário, ou seja, trazendo as comunidades para dentro da escola.

A valorização das culturas locais, o respeito à multiplicidade de experiências, valores e idéias na construção de ações para a sustentabilidade podem ser a chave para uma mobilização comunitária. Isso se constrói a partir de uma estreita relação que se tece entre a escola e seu entorno imediato, através de diagnósticos coletivos, encontros, eventos e efetiva participação na elaboração de propostas de ação. Movimentos estes que potencializam a instauração de coletivos engajados através do diálogo e da negociação.

A escola também poderá contribuir na identificação desses protagonistas, atores com potencial de liderança e mobilização, em seu meio institucional e no bairro, partilhando, então, com esse grupo, os conhecimentos científicos que possam responder à necessária tessitura de estratégias de empoderamento ${ }^{4}$ dessas comunidades locais. Isso se concretiza através de seus saberes e fazeres, da assunção e valorização de seu patrimônio natural territorial e do acesso aos processos decisórios sobre as possibilidades de atuação e intervenção dos representantes locais nos processos de gestão ambiental compartilhada. 
Entretanto, isso não é suficiente. É importante agregar novas formas de aprendizagem social, expansão dos lócus de aprendizado e de interpretação do cotidiano, de arenas de negociação e jogos de papéis. Essas estratégias podem ser entendidas como espaços de convivência e de formação de conhecimentos sobre aprendizagem social na gestão compartilhada e participativa do contexto socioambiental pertencente a esses sujeitos, resgatando o espírito de comunidade que, segundo Bauman (2003), significa o entendimento compartilhado do tipo "natural e tácito".

Também o desenvolvimento de práticas nos espaços de convivência, que superem o pragmatismo dominante de um conhecimentoregulação para o desenvolvimento de um conhecimento-emancipação, torna-se muito importante para a tessitura coletiva de projetos de intervenção na realidade, envolvendo os responsáveis políticos e a comunidade local. Todos são convidados a participar das reuniões, encontros, eventos e fóruns, dentro ou fora da escola. A intenção é estimular e criar espaços para sonhar o bairro onde vivem e construir planos de ação coletivos, fomentando práticas associativas de cooperação, mobilização e participação, em processos capazes de instaurar pactos entre os protagonistas locais e desenvolver relações de confiança mais solidárias e horizontalizadas.

No entanto, instaurar efetivamente uma escola voltada ao enfrentamento dos múltiplos desafios da atual sociedade de risco requer o enfrentamento dos próprios desafios colocados no interior de um sistema de ensino fragmentado e fundamentado em políticas de educação verticalizadas, emaranhado em seus próprios complicadores de caráter burocrático. Políticas que trazem em sua própria constituição uma série de entraves aos processos e práticas educativas de caráter dialógico, autônomo e democrático, e que se tornam, paradoxalmente, obstáculos ao aprendizado de processos de gestão participativa e co-responsável (Franco, 2006). Isso exige mudanças culturais e políticas radicais, a partir da formação de professoras e professores.

As propostas curriculares, as mudanças e transformações educativas dependem daqueles e daquelas envolvidos/as com seu cotidiano. $\mathrm{O}$ engajamento dos/as professores/as nos processos políticos de decisão, na participação em encontros e eventos, intervém no seu saber-fazer pedagógico e pode ser considerado como contexto valioso 
de formação, mas também como possibilidade de construção de novas formas de compreender e viver a relação exclusão e inclusão, saber e poder, teoria e prática (Tristão, 2007).

Nesse contexto de inseguranças e riscos, surge, ao mesmo tempo, a problemática da formação dos professores, de sua apropriação e sensibilização frente aos novos saberes, valores e princípios éticos necessários à adoção de novas posturas, hábitos e atitudes socioambientais. A cidadania, fundamentalmente, depende de uma ética integral de respeito à vida, a todos os seres com os quais compartilhamos o mundo, permeada pela cooperação e solidariedade. Numa opção de educação emancipatória e colaborativa, o/a professor/a pode potencializar a sua ação educativa, ao colocar-se a favor do diálogo, da participação, do respeito às diferentes opiniōes e necessidades, de práticas educativas abertas, em currículos cotidianos que dialoguem com as demandas sociais e culturais da realidade local e planetária.

\section{Recebido em janeiro de 2008 e aprovado em outubro de 2008.}

\section{Notas}

1. A idéia de desenvolvimento sustentável deriva do conceito de ecodesenvolvimento proposto por Ignacy Sachs e Maurice Strong (Estocolmo, 1972). Este conceito deu origem ao Programa das Naçōes Unidas para o Meio Ambiente e foi incorporado definitivamente na Conferência das Nações Unidas sobre Meio Ambiente e Desenvolvimento em 1992 - ECO92. O controverso conceito de desenvolvimento sustentável coloca-se, hoje, como uma questão polêmica para a educação ambiental, porque há uma discussão internacional sobre a polarização criada pela UNESCO entre desenvolvimento sustentável e sociedades sustentáveis, ao declarar esta a década da Educação para o desenvolvimento sustentável (20052014).

2. Aqui partimos da concepção de uma comunidade ou sujeito coletivo que se forma em torno de uma proposta de intervenção na realidade local, que compartilha processos de aprendizagem em contextos socioculturais, onde todos contribuem com experiências e conhecimentos na busca de propostas de soluções para a melhoria da qualidade de vida e das relaçôes.

3. Referimo-nos aos professores, direção, alunos, inspetores, merendeiras, representantes da Associação de Pais e Mestres (APM), grêmio estudantil; e da comunidade onde a escola está inserida: famílias, moradores do bairro, comércio local que integram os setores da educação formal e não-formal, através da atuação e colaboração das diversas instâncias sociais que compõem o conjunto de práticas socioeducativas.

4. Através do conhecimento situado, contextualizado, crítico e reflexivo, atores locais podem desenvolver condições para intervir na realidade. 
A função social da educação ambiental nas práticas colaborativas...

\section{Referências}

ARNSTEIN, S.R. Uma escada da participação cidadã. Revista da Associação Brasileira para o Fortalecimento da Participação - Participe, Porto Alegre/Santa Cruz do Sul, v. 2, n. 2, p. 4-13, 2002.

BAUMAN, Z. Modernidade líquida. Rio de Janeiro: Zahar, 2001.

BAUMAN, Z. Comunidade: a busca por segurança no mundo atual. Rio de Janeiro: Zahar, 2003.

BECK, U. A reinvenção da política. In: Giddens, A. et al. Modernização reflexiva. São Paulo: UNESP, 1997.

CARIDE, J.; MEIRA, P. Eduación ambiental y desarrollo humano. Barcelona: Ariel, 2001.

DALLARI, D.A. Elementos de teoria geral do Estado. São Paulo: Saraiva, 2003.

FRANCO, M.I. Agenda 21 na educação: construindo ferramentas pedagógicas para trilhar o caminho da sustentabilidade. In: Agenda 21 - Educação ambiental em áreas de proteção aos mananciais. São Paulo/Embu: Fundo Estadual de Recursos Hídricos, 2006. p. $8-18$

GIDDENS, A. Consequências da modernidade. São Paulo: UnesP, 1992.

GIROUX, H. Os professores como intelectuais: rumo a uma pedagogia crítica da aprendizagem. Porto Alegre: ARTMED, 1997.

GIROUX, H. Atos impuros: a prática política dos estudos culturais. Porto Alegre: ARTMED, 2003.

GUIMARÃES, R. La sostenibilidad del desarrollo entre Rio-92 y Johannesburgo 2002: eramos felices y no sabiamos. Ambiente \& Sociedade, Campinas, n. 9, p. 5-24, 2001.

HARMONICOP Project, 2003. Disponível em: <http://www. harmonicop.uos.del_files_down/brochureharmonicopen.pdf $>$. Acesso em: 24 mar. 2007. 
JACOBI, P.R. Meio ambiente urbano e sustentabilidade: alguns elementos para a reflexão. In: Cavalcanti, C. (Org.). Meio ambiente, desenvolvimento sustentável e políticas públicas. São Paulo: Cortez, 1997.

JACOBI, P.R. Educação ambiental, cidadania e sustentabilidade. Cadernos de Pesquisa, São Paulo, n. 118, p. 189-205, 2003.

JACOBI, P.R. A gestão participativa de bacias hidrográficas no Brasil e os desafios do fortalecimento de espaços colegiados. In: Nobre, M.; Schattan, V. (Org.). Participação e deliberação: teoria democrática e experiências institucionais no Brasil contemporâneo. São Paulo: Editora 34, 2004. p. 270-289.

JACOBI, P.R. Educação ambiental: o desafio da construção de um pensamento crítico, complexo e reflexivo. Educação \& Pesquisa, São Paulo, v. 31, n. 2, p. 233-250, maio/ago. 2005.

MATURANA, H. Emoções e linguagem na educação e na política. Belo Horizonte: UFMG, 1998.

MORIN, E. A cabeça bem-feita: repensar a reforma - reformar o pensamento. Rio de Janeiro: Bertrand Brasil, 2000.

SANTOS, B.S. A crítica da razão indolente: contra o desperdício da experiência. 2. ed. São Paulo: Cortez, 2000.

TRISTÃO, M. Tecendo os fios da educação ambiental: o subjetivo e o coletivo, o pensado e o vivido. Educação \& Pesquisa, São Paulo, v. 31, n. 2, p. 251-264, maio/ago. 2005.

TRISTÃO, M. A educação ambiental e os contextos formativos na transição de paradigmas. In: REUNIÃO ANUAL DA ANPEd, 30., 2007, Caxambu. Anais... Caxambu: ANPEd, 2007.

TRISTÃO, M.; FASSARELA, R. Contextos de aprendizagem. In: Encontros e caminhos: formação de educadoras (es) ambientais e coletivos educadores. Brasília, DF: MMA, 2006. v. 2.

VEIGA, J.E. Desenvolvimento sustentável: o desafio do século XXI. Rio de Janeiro: Garamond, 2005. 